\title{
Important regulatory function of transient receptor potential ankyrin 1 receptors in age-related learning and memory alterations of mice
}

\author{
Éva Borbély • Maja Payrits • Ágnes Hunyady • \\ Gréta Mező • Erika Pintér
}

Received: 21 November 2018 / Accepted: 2 July 2019/Published online: 20 July 2019

(C) The Author(s) 2019

\begin{abstract}
Expression of the transient receptor potential ankyrin 1 (TRPA1) receptor has been demonstrated not only in the dorsal root and trigeminal ganglia but also in different brain regions (e.g., hippocampus, hypothalamus, and cortex). However, data concerning their role in neurodegenerative and age-related diseases of the CNS is still indistinct. The aim of our study was to investigate the potential role of TRPA1 in a mouse model of senile dementia. For the investigation of changes during aging, we used male young (3-4-month-old) and old (18-monthold) wild-type (TRPA $1^{+/+}$;WT) and TRPA1 receptor genedeleted (TRPA $1^{-/}$) mice. Novel object recognition (NOR) test as well as Y maze (YM), radial arm maze (RAM), and Morris water maze (MWM) tests were used to assess the decline of memory and learning skills. In the behavioral studies, significant memory loss was detected in aged $\mathrm{TRPA}^{+/+}$mice with the NOR and RAM, but there was no difference measured by YM and MWM tests regarding the age and gene. TRPA1 ${ }^{-/}$showed significantly reduced memory loss, which could be seen as higher discrimination index in the NOR and less exploration time in the RAM. Furthermore, young TRPA $1^{-/-}$animals showed
\end{abstract}

Éva Borbély and Maja Payrits contributed equally to this work.

É. Borbély · M. Payrits · Á. Hunyady · G. Mező · E. Pintér Department of Pharmacology and Pharmacotherapy, Medical School, University of Pécs, Szigeti u.12., Pécs 7624, Hungary

É. Borbély · M. Payrits · Á. Hunyady • E. Pintér $(\square)$ Szentágothai Research Center, Center for Neuroscience, University of Pécs, Ifjúság u. 20, Pécs 7624, Hungary e-mail: erika.pinter@aok.pte.hu significantly less reference memory error in the RAM and notably higher mobility in NOR, RAM, and YM compared with the age-matched WTs. Our present work has provided the first evidence that TRPA1 receptors mediate deteriorating effects in the old age memory decline. Understanding the underlying mechanisms could open new perspectives in the pharmacotherapy of dementia.

Keywords TRPA $1 \cdot$ Learning $\cdot$ Memory $\cdot$ Dementia

\section{Introduction}

Transient receptor potential ankyrin 1 (TRPA1) is a polymodal, non-selective cation channel, which belongs to the TRP superfamily. It is widely expressed on neuronal and non-neuronal cell types (Nilius et al. 2012). The highest level of expression can be detected in the nervous system - primarily in the dorsal root and trigeminal ganglia as well as in capsaicin-sensitive sensory nerve endings (Zygmunt and Högestätt 2014). It plays a crucial role in several physiological and pathophysiological processes: pain sensation (Kádková et al. 2017; Hung and Tan 2018), inflammation (Koivisto et al. 2014; Choi and Di Nardo 2018), and cancer (Büch et al. 2018).

TRPA1 has also been shown in the central nervous system (CNS). It was detected in the hippocampus (Koch et al. 2011), nucleus supraopticus of the hypothalamus (Yokoyama et al. 2011), brain stem (Sun et al. 2009), and cortical neurons (Kheradpezhouh et al. 
2017). Furthermore, TRPA1 receptors are expressed in astrocytes and play a role in the regulation of the intracellular calcium level resulting in the release of mediators (Shigetomi et al. 2011, 2013; Takizawa et al. 2018). Therefore, TRPA1 was recently intensively investigated in different central nervous system pathologies, e.g., multiple sclerosis (Sághy et al. 2016; Bölcskei et al. 2018) and Alzheimer's disease (Lee et al. 2016). Additionally, due to its expression on endothelial cells, oxygen sensing, and calcium-regulating functions, TRPA1 has neuroprotective effects also in stroke (Pires and Earley 2018; Guerra et al. 2018). Moreover, TRPA1 seems to be a key contributor of ischemic myelin damage (Hamilton et al. 2016). These results strongly suggest that TRPA1 influences the neuroinflammatory/ neurodegenerative alterations. However, results concerning the age-related expression and functional changes of TRPA1 are deficient. TRPA1 expression continuously increases in the mouse brain after birth but reaches a plateau in 2-3 weeks (Lee et al. 2017). Data about alterations of the receptor count/density in older animals are absolutely lacking. There is only one paper that compares the function of TRPA1 in young (3month-old) and aged (24-month-old) mice. They have found that TRPA1 is a key mediator of nociceptor sensitization only in aged animals in an adjuvantinduced arthritis model (Garrison and Stucky 2014).

The mechanism of senile memory loss is still unclear. This type of dementia is usually moderate but it gradually leads to declined mental function, resulting in disability and loss of quality of life (Bowling et al. 2015). There are several neurodegenerative processes involved in senile dementia (Blalock et al. 2003). The most important factors are inflammatory responses (HaussWegrzyniak et al. 2000; Andreasson et al. 2001; Franceschi and Campisi 2014), oxidative stress (Carney et al. 1991; Davies et al. 2017; Tan et al. 2018), mitochondrial dysfunction, and altered calcium homeostasis (Alzheimer's Association Calcium Hypothesis Workgroup 2017; Müller et al. 2018; Sure et al. 2018). Investigation of the molecular background of this type of memory loss as well as the assessment of the effectiveness of different drug candidates is very complicated in rodents. Dementia occurs as a complex syndrome of cognitive, functional, and emotional alterations in humans (Ferrucci et al. 2018; Cansino et al. 2018); only some symptoms are reproducible in animal models (Mitchell et al. 2015; Wahl et al. 2017). Furthermore, the mortality, morbidity, and sensitivity to different interventions have much higher risk over 12 months in rodents (Snyder et al. 2016).

TRPA1 channel is a "promiscuous" receptor and can be activated by several electrophilic ligands (free radicals, inflammatory mediators, etc.) (Bandell et al. 2004; Nilius et al. 2012; Storozhuk and Zholos 2018; Pozsgai et al. 2019) which accumulate during aging. TRPA1 activation leads to increased intracellular calcium level with cellular damage aggravating dementia in a genetic mouse model of Alzheimer's disease. Therefore, in the present study, we aimed to investigate the old age memory decline without any pharmacological or genetic manipulation. Another aim was to investigate the potential role of TRPA1 receptors in senile dementia in genedeleted mice.

\section{Materials and methods}

\section{Ethics}

All experimental procedures were performed according to the 1998/XXVIII Act of the Hungarian Parliament on Animal Protection, Consideration Decree of Scientific Procedures of Animal Experiments (243/1988), Hungarian regulations (40/2013, II.14.), and Directive 2010/63/EU of the European Parliament. The studies were approved by the Ethics Committee on Animal Research of University of Pécs according to the Ethical Codex of Animal Experiments and license was given (license no. BA 02/2000-24/2016).

Animals

Experiments were carried out using TRPA1 receptor gene-deficient mice (TRPA $1^{-/-}$; KO) and their wildtype counterparts $\left(\mathrm{TRPA}^{+/+}\right.$; WT), respectively. $\mathrm{TRPA}^{-/-}$and $\mathrm{TRPA}^{+/+}$mice were generated from an original pair of heterozygous mice and obtained from Prof. P. Geppetti (University of Florence, Italy). Offspring were genotyped and homozygous mice were selected for further breeding. The animals were bred and kept in the vivarium of the Department of Pharmacology and Pharmacotherapy of the University of Pécs at $24{ }^{\circ} \mathrm{C}$ and provided with standard rodent food and water ad libitum. The animals were maintained under conditions of 12-h light/dark cycle and were housed in groups of 3-5 in polycarbonate cages $\left(530-\mathrm{cm}^{3}\right.$ floor space, $14-\mathrm{cm}$ height) on wood 
shavings bedding. The animals had a $60-\mathrm{min}$ acclimatization period prior to each experiment.

For the experiments, young (3-4-month-old) and old (18-month-old) male TRPA $1^{+/+}$and TRPA $1^{-/-}$mice were used. The number of animals was 6-12/group.

Novel object recognition test (NOR)

For the assessment of the recognition memory, we used the well-known paradigm of the novel object recognition test (Morellini 2013). The examination lasted for 3 days. On the first, habituation day, animals could freely explore the $45 \times 45 \times 30 \mathrm{~cm}$ wooden box for a 5 -min-long period, which can be considered as a simple open field test. In this regard, spontaneous locomotor activity can be detected and characterized by distance moved, velocity, time spent in the center, and entries to the central zone. On the second experimental day, mice were allowed to examine the two identical objects for $5 \mathrm{~min}$. On the third day ( $24 \mathrm{~h}$ after the second trial), the animals could choose from one familiar and one novel object which has similar size but different shape and color. Mice explored the objects for $5 \mathrm{~min}$. Behavior of animals was recorded and analyzed with Ethovision XT11 software (Noldus Information Technology, Netherlands). The obtained data were calculated and represented as follows: distance moved, time spent with moving, velocity (1st, 2nd, 3rd days); location preference $=($ time exploring the right identical object/total exploration time) $\times 100$ (2nd day); recognition index = (time exploring the novel object/total exploration time) $\times 100$ and discrimination index $=$ difference in time exploring the novel and familiar objects/total exploration time, exploration time of the familiar and novel objects (3rd day).

\section{Radial arm maze test (RAM)}

For the measurement of short- and long-term memory alterations, the radial arm maze test is a widely used, suitable method (Levin 1988). Three-day-long habituation and learning period was used before the test trial. During this time, mice have to learn where they can find the food pellets (Dustless Precision Pellets ${ }^{\circledR} 45 \mathrm{mg}$, Sucrose; BioServ, USA) placed into 4 previously chosen arms of the eight-arm radial maze (arms $5 \times 35 \mathrm{~cm}$, central platform diameter $5 \mathrm{~cm}$ ). The trials lasted for $5 \mathrm{~min}$ or until the animals have found all the four food pellets, whichever came first. The learning ability was assessed on the 4th day of the experiment. Exploratory behavior was recorded and analyzed with Ethovision XT11 software (Noldus Information Technology, Netherlands). Data were calculated and represented as follows: working memory errors $=$ entries into the baited arms that had already been visited during the same trial, referring to the short-term memory, and reference memory error = entries into empty arms, showing the status of long-term memory, velocity, and average exploration time $=$ time spent in collecting all the pellets in the maze/total number of arm entries (Li et al. 2011; Zhang et al. 2000).

\section{Y maze test (YM)}

For the assessment of spatial memory, Y maze test was used (D'Souza et al. 2015; Hughes 2004). Only one 5min-long trial was performed in the equipment (three 35-cm-long $\times 5$-cm-wide arms, stated as A, B, and C arms) and the spontaneous alternation (correct alternating behavior (ABC, ACB, BAC, BCA, CAB, CBA)/the number of arm entries minus two); distance moved, velocity, and total number of arm entries were determined on the basis of the video tracked by Ethovision XT11 software (Noldus Information Technology, Netherlands).

\section{Morris water maze test (MWM)}

Morris water maze test is also widely used for both basic research and drug developmental purposes (D'Hooge and De Deyn 2001). It was originally developed for rats (Morris 1981), but later it was adapted to mice. In our hands, the following protocol was used: a circular pool was filled with water to hide the platform placed always at the same point of the pool. Visual clues were placed above the pool on the wall to help the orientation. Conditioning lasted for 3 days; each day, each animal performed 4 swimming sessions started from 4 different points of the pool (northeast (NE), southeast (SE), southwest (SW), and northwest (NW)). On the fourth day of the study, all mice had to perform the same 4 swimming sessions, and the time to find the platform (escape latency) was calculated as the mean of the 4 trials (Zhang et al. 2012). Swimming time was recorded and analyzed with Ethovision XT11 software (Noldus Information Technology, Netherlands). 


\section{Heat maps}

Different colors indicated by the heat maps show the average activity of the animal groups. It shows how and where the animals spent time during the tests. Cold colors (black, blue, and green) mean low activity. Warm colors (yellow, red) indicate high activity of the mice in different parts of the experimental area.

Statistical analysis

Data in all experiments were expressed as mean \pm SEM. Data are analyzed by two-way ANOVA followed by Fischer's posttest. In case of location preference, one sample $t$ test in comparison with 50\% was used. In every case, $p<0.05$ was considered significant. All statistical analyses were performed using Statistica software.

\section{Results}

Significantly attenuated memory loss was detected in old TRPA $1^{-/}$animals by the NOR compared with the TRPA $1^{+/+}$respective controls

On the first day of the novel object recognition (NOR) test, when the animals can move around freely in the box, young $\mathrm{TRPA}^{-/-}$showed significantly higher mobility state. Young TRPA1 ${ }^{+/+}$mice moved $787.50 \pm$ $92.37 \mathrm{~cm}$ with a velocity of $3.39 \pm 0.23 \mathrm{~cm} / \mathrm{s}$, while these values in the case of the TRPA $1^{-/}$animals were $1511.00 \pm 184.80 \mathrm{~cm}$ and $5.71 \pm 0.68 \mathrm{~cm} / \mathrm{s}$, respectively (Fig. 1a, d). Velocity of old gene-deleted animals was also higher $(5.33 \pm 0.39 \mathrm{~cm} / \mathrm{s})$ than that of the WT counterparts $(3.07 \pm 0.39 \mathrm{~cm} / \mathrm{s})$. Time spent in the center zone was not significantly different in the different groups and did not markedly alter with the age, but the entries in the center zone (TRPA $1^{+/+} 7.33 \pm 1.56$, TRPA1 $\left.^{-/} 16.44 \pm 2.80\right)$ showed the higher mobility state of the TRPA1 ${ }^{-/}$animals again (Fig. 1e, f). Heat maps of the animals visualize the differences observed on the first day of the NOR. In case of both old and young TRPA $1^{-/}$mice, the density maps show more colorful areas and the center zone is also covered by blue color which cannot be detected in the case of the respective WTs (Fig. 1g-j).

On the second day, all animal groups showed no or minimal preference to one of the identical objects, so there was no significant location preference in any of the groups (Fig. 2a). The velocity was significantly higher in young TRPA1 ${ }^{-/-}$animals compared with the WT counterparts also on the 2 nd and 3rd days of the experiment (Fig. 1b, c).

In old TRPA $1^{+/+}$mice, the frequency of visiting the novel object $(1.37 \pm 0.42)$ and the discrimination index $(-0.44 \pm 0.25)$ was significantly deteriorated compared with the young TRPA $1^{+/+}$animals $(3.20 \pm 0.51$ and $0.31 \pm 0.10$; Fig. $2 b, d)$. In the gene-deleted animals, this memory loss cannot be detected; young and old TRPA $1^{-/}$showed similar performance during the test trial (Fig. 2b-d). In comparison with old TRPA $1^{+/+}$and TRPA $1^{-/-}$mice, the NOR memory test has shown that both the discrimination $(0.17 \pm 0.05)$ and recognition indexes $(55.08 \pm 3.95)$ of the TRPA $1^{-/}$group are significantly higher than those of the WTs (Fig. 2b, c). Heat maps (Fig. 2g-j) show the preference of the novel (right) object in every group except for the old TRPA $1^{+/+}$. The most frequently visited place was very close to the novel object (top right corner) in the young groups.

Young animals showed significantly better reference memory compared with the old animals, and attenuated memory loss was detected in old TRPA1 KO mice compared with the WT controls in the RAM

The radial arm maze (RAM) test showed that old $\mathrm{TRPA}^{+/+}$and TRPA $1^{-/-}$mice need longer time for exploration than the young animals. Additionally, old TRPA $1^{-/}$animals spend significantly less time (343.50 $\pm 60.17 \mathrm{~s}$ ) with collecting the pellets than the old TRPA $^{+/+}(545.00 \pm 47.45)$ mice (Fig. 3c). Furthermore, old TRPA $1^{+/+}$mice find significantly less rewards ( 2.50 \pm 0.42 ) compared with the young WT counterparts $(3.70 \pm 0.21)$, which decline cannot be observed in the case of the gene-deleted animals (Fig. 3d). The velocity was significantly higher in the young TRPA $1^{-/}$group compared with the WTs and remarkably decreased in aged TRPA $1^{-/}$animals (Fig. 3e).

The reference memory error is significantly higher in the old groups $\left(\mathrm{TRPA}^{+/+} 4.50 \pm 0.22\right.$; $\mathrm{TRPA}^{-/-} 4.50$ $\pm 0.29)$ compared with their young counterparts $\left(\mathrm{TRPA}^{+/+} 2.67 \pm 0.33\right.$; $\left.\mathrm{TRPA}^{-/-} 1.40 \pm 0.24\right)$. Furthermore, it was remarkably lower in young TRPA $1^{-/}$mice than in WTs (Fig. 3b). The working memory error is significantly higher in old animals (TRPA $1^{+/+} 2.40 \pm$ 0.40 ; TRPA $\left.^{-/-} 1.50 \pm 0.22\right)$ compared with the young groups $\left(\mathrm{TRPA}^{+/+} 0.67 \pm 0.29\right.$; $\mathrm{TRPA}^{-/-} 0.25 \pm 0.16$ ), and it is lower in both young and old TRPA $1^{-/}$animals 

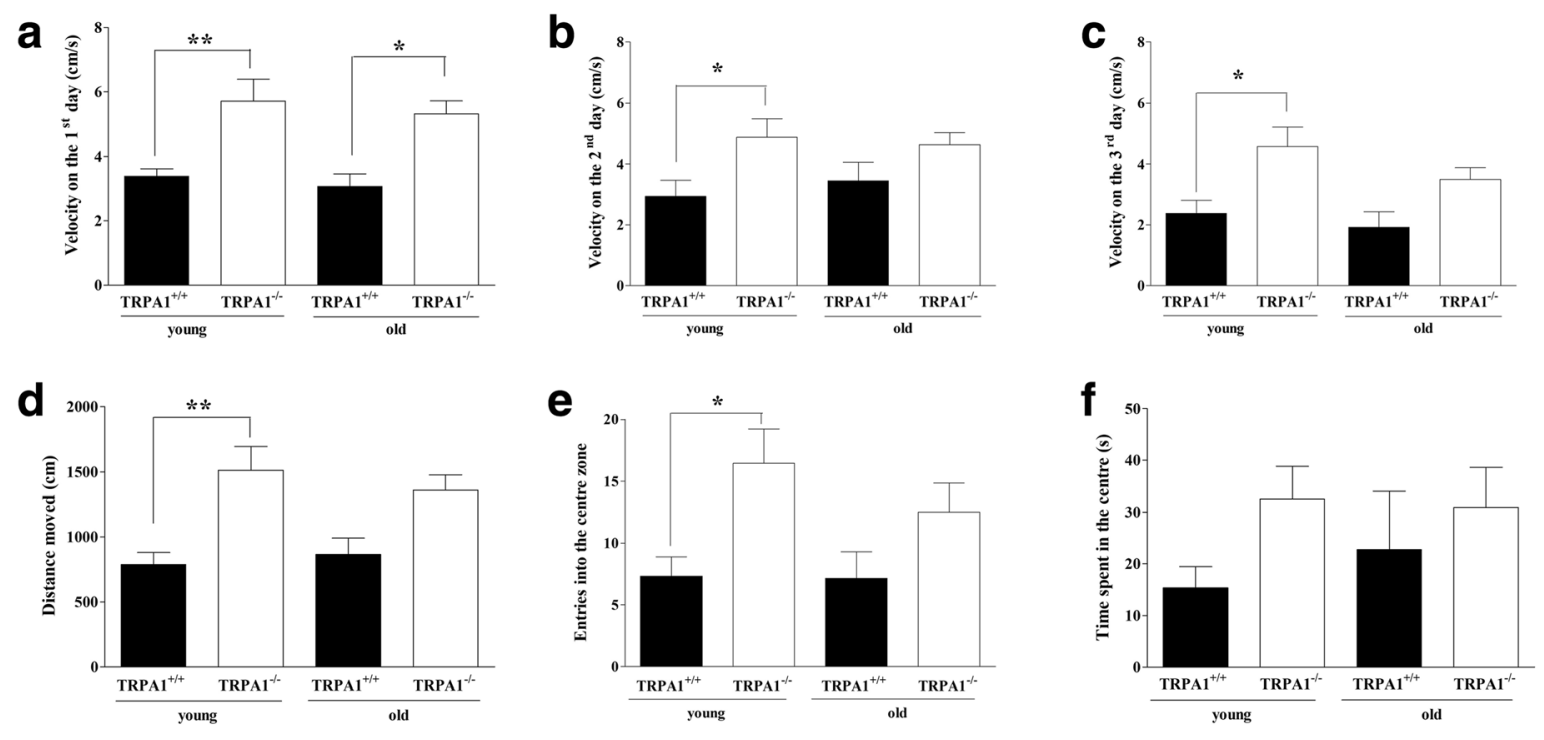
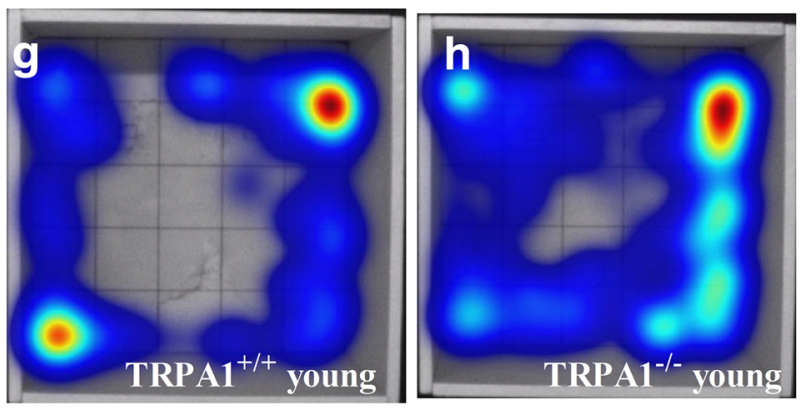

Fig. 1 Age-dependent changes of the performance in the open field test (OFT)/1 st day of novel object recognition (NOR) task in $\mathrm{TRPA}^{+/+}$and TRPA $1^{-/-}$young and old mice. Spontaneous locomotor activity was determined as velocity (a) and distance moved (d) as well as entries to the center zone (e). Anxiety level was assessed by the time spent in the center zone (f). Velocity was determined also on the 2nd (b) and 3rd (c) days of the NOR test. Data are presented as the mean \pm SEM $(n=6-10)$ and were

compared with their WTs, although it is not statistically significant (Fig. 3a). Heat maps clearly demonstrate that the young animals visited markedly less arm and made less errors compared with the old mice (Fig. $3 \mathrm{f}-\mathrm{i}$ ).

Neither age nor TRPA1 gene deletion influenced the Y maze and Morris water maze test performance

Spontaneous alternation measured in the $\mathrm{Y}$ maze was very similar in all investigated groups, approximately $67 \%$ (Fig. 4a). Furthermore, despite the higher mobility of the young TRPA $1^{-/}$group $(1218.00 \pm 86.60 \mathrm{~cm}, 3.832 \pm 0.5022 \mathrm{~cm} / \mathrm{s}$; Fig. 4c, d), which tendency was similar to the
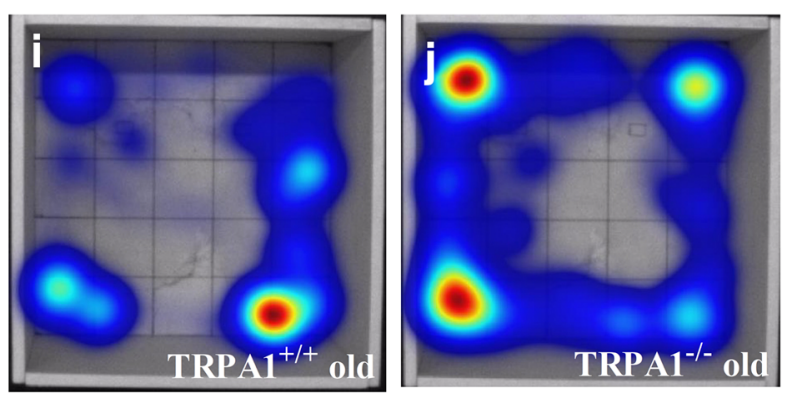

analyzed by two-way ANOVA followed by Fischer's posttest $(* p<0.05, * * p<0.01)$. Demonstrative heat map pictures of the locomotor activity of TRPA $1^{+/+}$young (g) and old (i) as well as TRPA $^{-/-}$young $(\mathbf{h})$ and old (j) mice on the 1 st day of the NOR test. Blue color represents the less visited parts of the experimental area; red color represents the most frequently visited parts of the experimental area

NOR test, the number of arm entries was very similar in all groups, approximately 16 (Fig. 4b).

Escape latency measured in the Morris water maze test did not show any significant difference neither

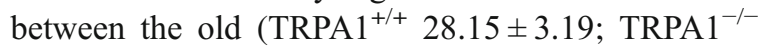
$28.47 \pm 4.04$ ) and young groups (TRPA $1^{+/+} 31.69 \pm$ 3.04; TRPA $\left.^{-/-} 27.78 \pm 2.70\right)$ nor between WT and gene-deleted animals (Fig. 4e).

\section{Discussion}

The present study has provided the first evidence that TRPA1 receptors are involved in senile memory 
a



d

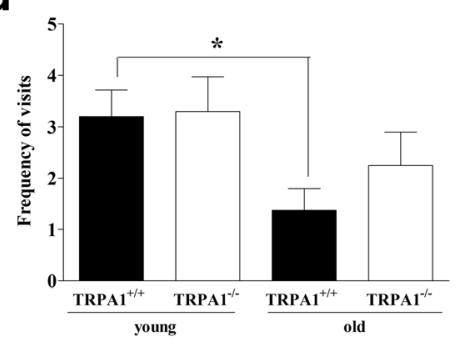

b



e

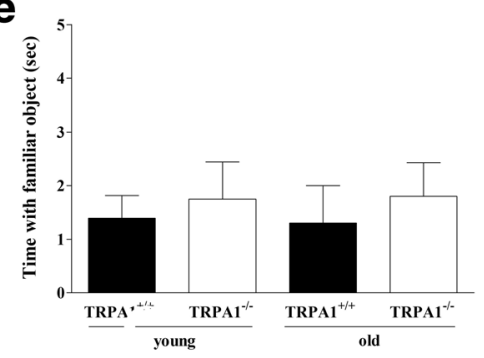

$\mathbf{C}_{8}$

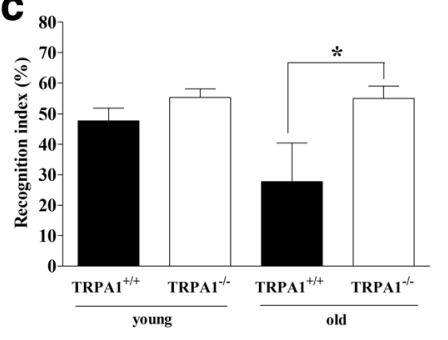

f

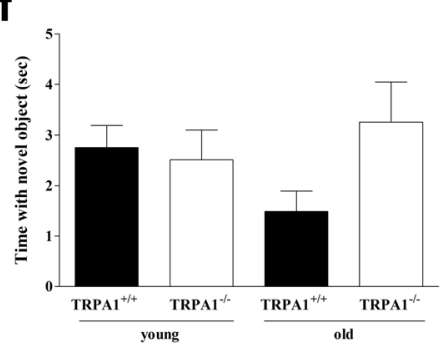

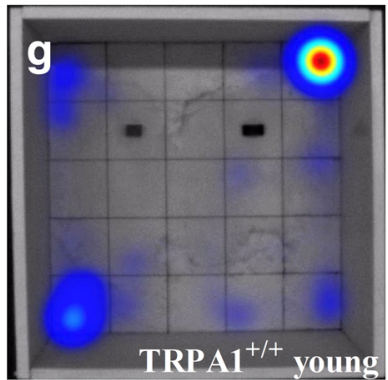

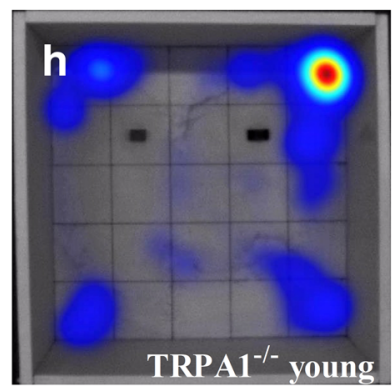

Fig. 2 Age-dependent changes of the performance in the novel object recognition (NOR) task in TRPA $1^{+/+}$and TRPA $1^{-/}$young and old mice. On the 2nd day of the test, time spent with exploring the two identical objects was demonstrated as location preference (a). Memory function was determined on the 3rd (test) day as discrimination index (b), recognition index (c), frequency of visiting the objects (d), and time spent with exploring the familiar (e) and novel (f) objects. Data are presented as the mean $\pm \operatorname{SEM}(n=$

loss of mice. We were able to assess memory decline with the NOR and RAM tests, while the spontaneous alternation in $\mathrm{Y}$ maze (YM) and the escape latency in Morris water maze (MWM) tests did not demonstrate the age-related downtrend of learning ability in our model.

TRPA1 is widely expressed throughout the body. It is localized in the peripheral, as well as the central nervous systems. There is strong evidence that TRPA1 plays a crucial role in pain transmission (Koivisto et al. 2018) and neuroimmune interactions (López-Requena et al. 2017). Therefore, it could be a potential drug target for several pain-related, respiratory, and vascular disorders (Nishida et al. 2015). However, studies of the last decade focused more and more to the CNS expressions
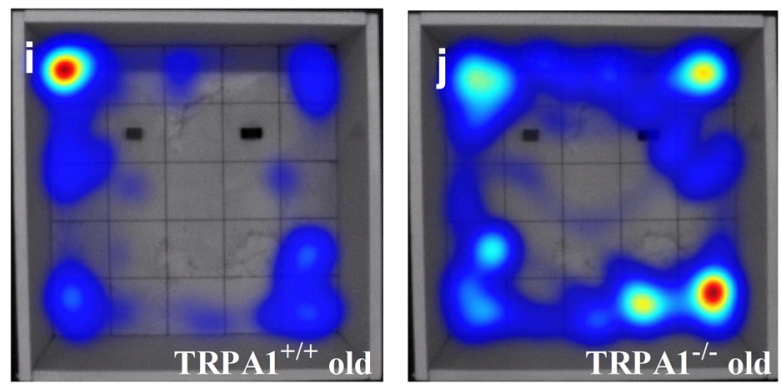

6-10) and were analyzed by two-way ANOVA followed by Fischer's posttest $(* p<0.05)$. In the case of location preference, one sample $t$ test in comparison with $50 \%$ was used. Heat map pictures of the performance of TRPA $1^{+/+}$young (g) and old (i) as well as TRPA $1^{-/}$young $(\mathbf{h})$ and old $(\mathbf{j})$ mice on the 3 rd day of the NOR test. Blue color represents the less visited parts of the experimental area; red color represents the most frequently visited parts of the experimental area

and functions of TRPA1. There is an increasing evidence that TRPA1 can be found in the brain; both neuronal (cortex, hypothalamus, and hippocampus) and non-neuronal (astrocytes, Schwann cells, and endothelial cells) cell types express the receptor (Meents et al. 2019). Although our knowledge about TRPA1 functions in the CNS is limited (Sághy et al. 2016; Lee et al. 2017; Shigetomi et al. 2013; Lee et al. 2016), due to its polymodal nature, TRPA1 is very likely to be involved in numerous brain pathologies. A wide range of ligands, irritants, or stimulants can activate or sensitize the receptor (Nilius et al. 2012; Pozsgai et al. 2019; Chen and Hackos 2015). Furthermore, the consequence of TRPA1 activation can also be linked to CNS processes, because these receptors are highly permeable to 


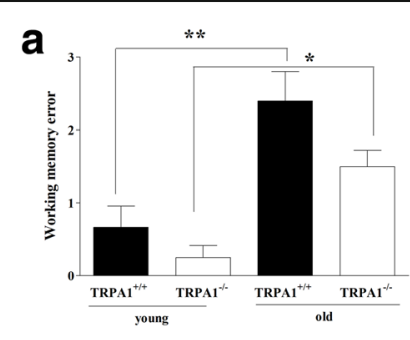

b

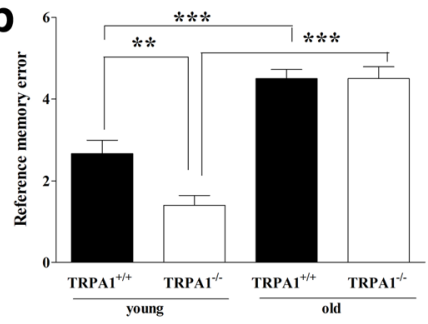

C

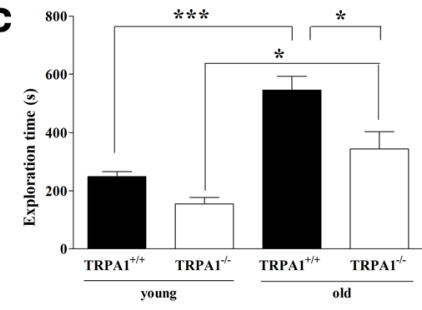


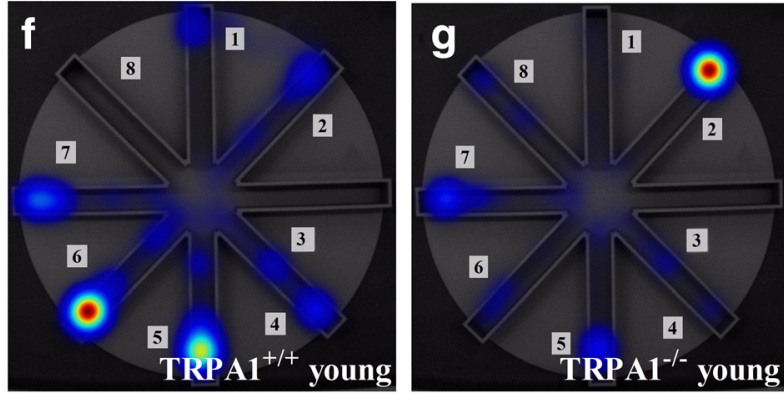

Fig. 3 Age-dependent changes of the performance in the radial arm maze (RAM) task in TRPA $1^{+/+}$and TRPA $1^{-/-}$young and old mice. Memory function was determined as working memory error (a), reference memory error (b), average exploration time (c), and rewards found (d). Velocity of the animals (e) was also assessed during the measurement. Data are presented as the mean \pm SEM $(n=6-10)$ and were analyzed by two-way ANOVA followed by
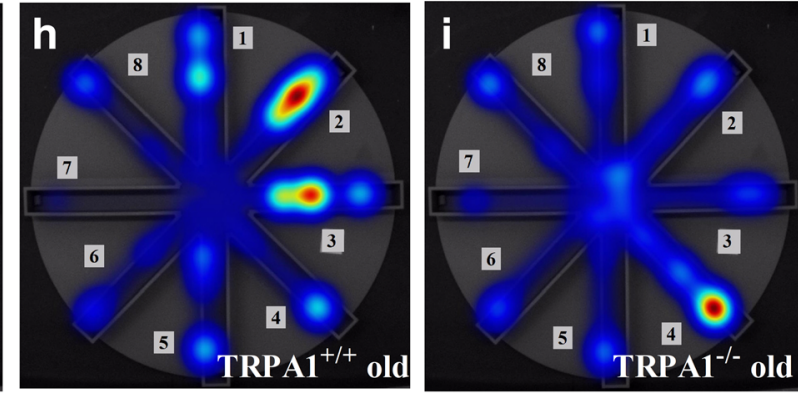

Fischer's posttest $(* p<0.05, * * p<0.01, * * * p<0.001)$. Heat map pictures of the performance of TRPA $1^{+/+}$young (f) and old (h) as well as TRPA $1^{-/}$young (g) and old (i) mice on the 4th day of the RAM test. Blue color represents the less visited parts of the experimental area; red color represents the most frequently visited parts of the experimental area. Arms 1,2,5, and 7 were rewarded

mice showed marked memory loss and this alteration was significantly attenuated, nearly diminished in TRPA $1^{-/}$animals. Both discrimination and recognition indexes, as well as the frequency of visiting the objects, were higher in knockouts. In the present study, the RAM test also indicated remarkable difference between the young WT and TRPA1 KO groups concerning memory function. Reference memory error was significantly lower in young animals lacking TRPA1 compared with the WTs. Furthermore, old WT animals needed significantly more time to find the rewards in the maze than TRPA1 knockouts, and only old WT animals found significantly less rewards compared with the young counterparts. These results clearly confirm the results obtained from a genetic model of Alzheimer's disease. TRPA1 depletion leads to could also be detected in old animals: aged WT 
a



C

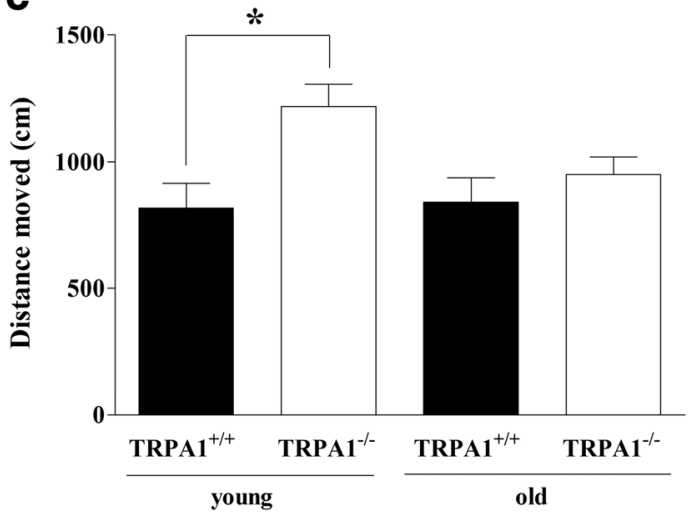

b

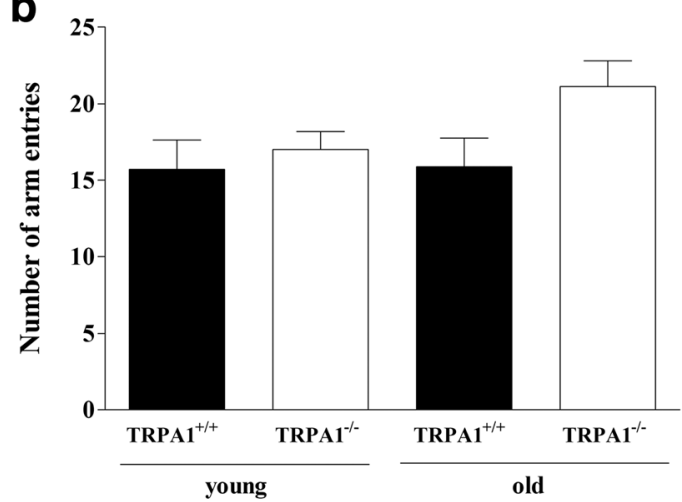

d

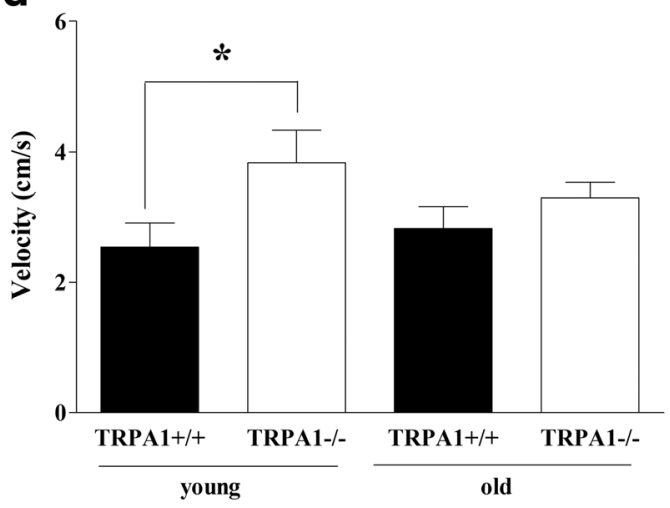

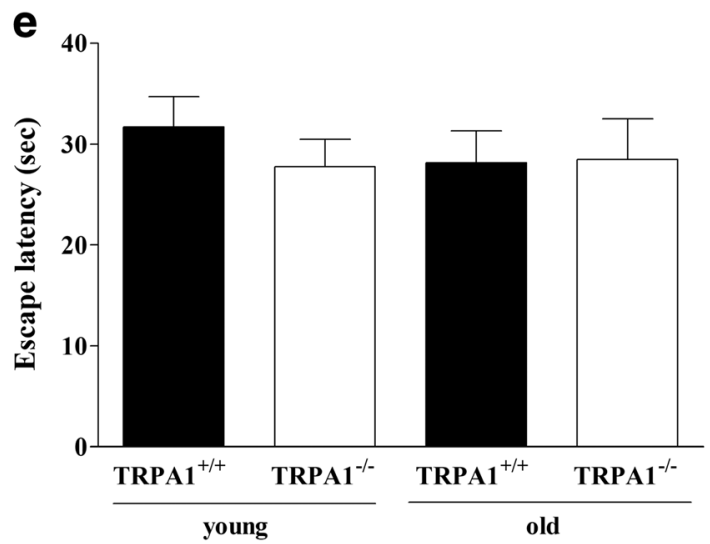

Fig. 4 Age-dependent changes of the performance in the Y maze (YM) and Morris water maze (MWM) tasks in TRPA $1^{+/+}$and TRPA $^{-/-}$young and old mice. Memory function was determined as spontaneous alternation (a), locomotor activity as number of

significantly reduced memory loss in both models (Lee et al. 2016).

There are several various processes which can lead to age-related diseases. Due to the heterogeneity of the arm entries (b), distance moved (c), and velocity (d) in YM. In the MWM, memory function was assessed as escape latency (e). Data are presented as the mean $\pm \operatorname{SEM}(n=6-10)$ and were analyzed by two-way ANOVA followed by Fischer's posttest $(* p<0.05)$

pathomechanisms, several mediators (pituitary adenylate cyclase-activating polypeptide, brain-derived neurotrophic factor, corticotropin-releasing factor, etc.) have recently been identified to be involved in the 
development of different disorders of aged animals/ humans (Reglodi et al. 2018; Ungvari et al. 2017; Vedovelli et al. 2017; Fang et al. 2017; Tenk et al. 2017; Ashpole et al. 2017). Altered inflammatory responses and upregulation of genes encoding inflammatory mediators (Blalock et al. 2003; Hauss-Wegrzyniak et al. 2000; Andreasson et al. 2001; Franceschi and Campisi 2014), as well as cumulating oxidative stress and the oxidative damage of proteins (Carney et al. 1991; Davies et al. 2017; Tan et al. 2018), are wellknown, important contributors to dementia. Similarly, altered mitochondrial function and calcium homeostasis, which are essentially responsible for the normal function of the brain cells (Alzheimer's Association Calcium Hypothesis Workgroup 2017; Müller et al. 2018; Sure et al. 2018), can result in cell death and memory decline.

Our results fairly show that the lack of TRPA1 leads to significant attenuated memory loss in aged mice, suggesting that TRPA1 plays a crucial debating role in old age memory decline. According to the microarray data of the Human Brain Transcriptome Database and the Allen Brain Atlas, the TRPA1 expression in the human and murine brains is quite low, but it can be clearly detected. Its expression shows relatively high values in the temporal, prefrontal, primary auditory, and primary visual cortices and in the hippocampal area. Expression levels in the human brain do not change with age (Kang et al. 2011; Barrett et al. 2013; Hawrylycz et al. 2012). Although the underlying mechanisms are still unknown and need further investigations, several mediators involved in memory loss are known activators/sensitizers of TRPA1. We suggest that neuroinflammation and oxidative stress developing with age, together with increased vulnerability for oxidative stress in higher age (Carney et al. 1991), could lead to overactivation of the TRPA1 receptors. The increased $\mathrm{Ca}^{2+}$ influx to the cytoplasm, which alone, or together with potentiating the effects of other cation channels, like NMDA receptors, results in $\mathrm{Ca}^{2+}$ dysregulation of the cells leading to cell degeneration or cell death.

Another important aim of the study was to characterize the model. Aging of the animals leads to a much less robust memory loss than measured in other chemically or genetically induced dementia models. Therefore, it is difficult to find the most appropriate memory losssensitive behavioral tests. The NOR test is one of the most well-known methods for assessing memory function. Although the low exploration time should be considered a limitation of the NOR test, we demonstrated a significant decline of memory function in 18month-old WT animals. Adequacy of the NOR test was also demonstrated in other accepted, oxidative stress (D-galactose, doxorubicin)-evoked animal models (Kaviani et al. 2017; Keeney et al. 2018). Radial arm water maze is a more widely applied test in aging/ dementia studies compared with the RAM test (Buhusi et al. 2017; Sudduth et al. 2013); however, there are some data describing that dietary intake of natural toxins (Karlsson et al. 2009) or aging (Marighetto et al. 2008) can decrease learning ability measured by RAM test. It was absolutely a suitable method for the presentation of senile memory loss in the present study. Both working and reference memory errors increased significantly in aged mice compared with their younger counterparts. The exploration time was also longer in older animals, and old WT mice found significantly less rewards than young animals. In the present study, Y and Morris water maze tests did not show any difference between the young and old groups. The literature is also divergent in this question; the results are contradictory (Morgan et al. 2018; Hattori et al. 2016).

Nevertheless, dementia treatment is absolutely unsatisfactory: in most cases, only the mild cognitive decline can be corrected. Although several recommendations (including physical activity and diet) and programs (reality orientation training or cognitive stimulation therapy) are offered for patients with dementia in order to increase quality of life, there are no effective drugs on the market against severe memory loss. Since the TRPA1 receptor seems to be a key regulator of memory functions in younger and older ages in animal studies, receptor antagonists could open new perspectives in the pharmacotherapy of the senile dementia.

Funding information Open access funding provided by University of Pécs (PTE). The research was supported by ÚNKP-173-VI New National Excellence Program of the Ministry of Human Capacities, Richter Gedeon Talentum Foundation, Comprehensive Development for Implementing Smart Specialization Strategies at the University of Pécs (EFOP-3.6.1.-16-2016-00004); and The role of neuroinflammation in neurodegeneration: from molecules to clinics (EFOP-3.6.2-16-2017-00008); EFOP-3.6.3-VEKOP-162017-00009; Hungarian Brain Research Program 2 2017-1.2.1NKP-2017-00002 20765/2018/FEKUTSTRAT.

Compliance with ethical standards All experimental procedures were performed according to the 1998/XXVIII Act of the Hungarian Parliament on Animal Protection, Consideration Decree of Scientific Procedures of Animal Experiments (243/1988), Hungarian regulations (40/2013, II.14.), and Directive 2010/63/ 
EU of the European Parliament. The studies were approved by the Ethics Committee on Animal Research of University of Pécs according to the Ethical Codex of Animal Experiments and license was given (license no. BA 02/2000-24/2016).

Open Access This article is distributed under the terms of the Creative Commons Attribution 4.0 International License (http:// creativecommons.org/licenses/by/4.0/), which permits unrestricted use, distribution, and reproduction in any medium, provided you give appropriate credit to the original author(s) and the source, provide a link to the Creative Commons license, and indicate if changes were made.

\section{References}

Alzheimer's Association Calcium Hypothesis Workgroup (2017) Calcium hypothesis of Alzheimer's disease and brain aging: a framework for integrating new evidence into a comprehensive theory of pathogenesis. Alzheimers Dement 13:178182.e17. https://doi.org/10.1016/j.jalz.2016.12.006

Andreasson KI, Savonenko A, Vidensky S, Goellner JJ, Zhang Y, Shaffer A, Kaufmann WE, Worley PF, Isakson P, Markowska AL (2001) Age-dependent cognitive deficits and neuronal apoptosis in cyclooxygenase-2 transgenic mice. J Neurosci 21:8198-8209

Ashpole NM, Logan S, Yabluchanskiy A, Mitschelen MC, Yan H, Farley JA, Hodges EL, Ungvari Z, Csiszar A, Chen S, Georgescu C, Hubbard GB, Ikeno Y, Sonntag WE (2017) IGF-1 has sexually dimorphic, pleiotropic, and timedependent effects on healthspan, pathology, and lifespan. Geroscience. 39:129-145. https://doi.org/10.1007/s11357017-9971-0

Bandell M, Story GM, Hwang SW, Viswanath V, Eid SR, Petrus MJ, Earley TJ, Patapoutian A (2004) Noxious cold ion channel TRPA1 is activated by pungent compounds and bradykinin. Neuron 41:849-857

Barrett T, Wilhite SE, Ledoux P, Evangelista C, Kim IF, Tomashevsky M, Marshall KA, Phillippy KH, Sherman PM, Holko M, Yefanov A, Lee H, Zhang N, Robertson CL, Serova N, Davis S, Soboleva A (2013) NCBI GEO: archive for functional genomics data sets-update. Nucleic Acids Res 41(Database issue):D991-D995. https://doi.org/10.1093 /nar/gks1193

Blalock EM, Chen KC, Sharrow K, Herman JP, Porter NM, Foster TC, Landfield PW (2003) Gene microarrays in hippocampal aging: statistical profiling identifies novel processes correlated with cognitive impairment. J Neurosci 23:3807-3819

Bölcskei K, Kriszta G, Sághy É, Payrits M, Sipos É, Vranesics A, Berente Z, Ábrahám H, Ács P, Komoly S, Pintér E (2018) Behavioural alterations and morphological changes are attenuated by the lack of TRPA1 receptors in the cuprizoneinduced demyelination model in mice. J Neuroimmunol 320:1-10. https://doi.org/10.1016/j.jneuroim.2018.03.020

Bowling A, Rowe G, Adams S, Sands P, Samsi K, Crane M, Joly L, Manthorpe J (2015) Quality of life in dementia: a systematically conducted narrative review of dementia-specific measurement scales. Aging Ment Health 19:13-31. https://doi.org/10.1080/13607863.2014.915923

Büch TRH, Büch EAM, Boekhoff I, Steinritz D, Aigner A (2018) Role of chemosensory TRP channels in lung cancer. Pharmaceuticals (Basel) 11:E90. https://doi.org/10.3390 /ph11040090

Buhusi M, Etheredge C, Granholm AC, Buhusi CV (2017) Increased hippocampal ProBDNF contributes to memory impairments in aged mice. Front Aging Neurosci 9:284. https://doi.org/10.3389/fnagi.2017.00284

Cansino S, Torres-Trejo F, Estrada-Manilla C, Martínez-Galindo JG, Hernández-Ramos E, Ayala-Hernández M, GómezFernández T, Ramírez-González MD, Ruiz-Velasco S (2018) Factors that positively or negatively mediate the effects of age on working memory across the adult life span. Geroscience 40:293-303. https://doi.org/10.1007/s11357018-0031-1

Carney JM, Starke-Reed PE, Oliver CN, Landum RW, Cheng MS, Wu JF, Floyd RA (1991) Reversal of age-related increase in brain protein oxidation, decrease in enzyme activity, and loss in temporal and spatial memory by chronic administration of the spin-trapping compound N-tert-butyl-alphaphenylnitrone. Proc Natl Acad Sci U S A 88:3633-3636

Chen J, Hackos DH (2015) TRPA1 as a drug target-promise and challenges. Naunyn Schmiedeberg's Arch Pharmacol 388: 451-463. https://doi.org/10.1007/s00210-015-1088-3

Choi JE, Di Nardo A (2018) Skin neurogenic inflammation. Semin 40:249-259. https://doi.org/10.1007/s00281-0180675-z

D’Hooge R, De Deyn PP (2001) Applications of the Morris water maze in the study of learning and memory. Brain Res Brain Res Rev 36:60-90

Davies JMS, Cillard J, Friguet B, Cadenas E, Cadet J, Cayce R, Fishmann A, Liao D, Bulteau AL, Derbré F, Rébillard A, Burstein S, Hirsch E, Kloner RA, Jakowec M, Petzinger G, Sauce D, Sennlaub F, Limon I, Ursini F, Maiorino M, Economides C, Pike CJ, Cohen P, Salvayre AN, Halliday MR, Lundquist AJ, Jakowec NA, Mechta-Grigoriou F, Mericskay M, Mariani J, Li Z, Huang D, Grant E, Forman HJ, Finch CE, Sun PY, Pomatto LCD, Agbulut O, Warburton D, Neri C, Rouis M, Cillard P, Capeau J, Rosenbaum J, Davies KJA (2017) The oxygen paradox, the French paradox, and age-related diseases. Geroscience 39:499-550. https://doi.org/10.1007/s11357-017-0002-y

Fang Y, McFadden S, Darcy J, Hill CM, Huber JA, Verhulst S, Kopchick JJ, Miller RA, Sun LY, Bartke A (2017) Differential effects of early-life nutrient restriction in longlived GHR-KO and normal mice. Geroscience. 39:347-356. https://doi.org/10.1007/s11357-017-9978-6

Ferrucci L, Levine ME, Kuo PL, Simonsick EM (2018) Time and the metrics of aging. Circ Res 123:740-744. https://doi. org/10.1161/CIRCRESAHA.118.312816

Franceschi C, Campisi J (2014) Chronic inflammation (inflammaging) and its potential contribution to ageassociated diseases. J Gerontol A Biol Sci Med Sci Suppl 1:S4-S9. https://doi.org/10.1093/gerona/glu057

Garrison SR, Stucky CL (2014) Contribution of transient receptor potential ankyrin 1 to chronic pain in aged mice with complete Freund's adjuvant-induced arthritis. Arthritis Rheum 66:2380-2390. https://doi.org/10.1002/art.38724 
Guerra G, Lucariello A, Perna A, Botta L, De Luca A, Moccia F (2018) The role of endothelial $\mathrm{Ca} 2+$ signaling in neurovascular coupling: a view from the lumen. Int J Mol Sci 19:E938. https://doi.org/10.3390/ijms19040938

Hamilton NB, Kolodziejczyk K, Kougioumtzidou E, Attwell D (2016) Proton-gated $\mathrm{Ca}(2+)$-permeable TRP channels damage myelin in conditions mimicking ischaemia. Nature. 529: 523-527. https://doi.org/10.1038/nature16519

Hattori Y, Enmi J, Iguchi S, Saito S, Yamamoto Y, Tsuji M, Nagatsuka K, Kalaria RN, Iida H, Ihara M (2016) Gradual carotid artery stenosis in mice closely replicates hypoperfusive vascular dementia in humans. J Am Heart Assoc 5:e002757. https://doi.org/10.1161 /JAHA.115.002757

Hauss-Wegrzyniak B, Vannucchi MG, Wenk GL (2000) Behavioral and ultrastructural changes induced by chronic neuroinflammation in young rats. Brain Res 859:157-166

Hawrylycz MJ, Lein ES, Guillozet-Bongaarts AL, Shen EH, Ng L, Miller JA, van de Lagemaat LN, Smith KA, Ebbert A, Riley ZL, Abajian C, Beckmann CF, Bernard A, Bertagnolli D, Boe AF, Cartagena PM, Chakravarty MM, Chapin M, Chong J, Dalley RA, David Daly B, Dang C, Datta S, Dee N, Dolbeare TA, Faber V, Feng D, Fowler DR, Goldy J, Gregor BW, Haradon Z, Haynor DR, Hohmann JG, Horvath S, Howard RE, Jeromin A, Jochim JM, Kinnunen M, Lau C, Lazarz ET, Lee C, Lemon TA, Li L, Li Y, Morris JA, Overly CC, Parker PD, Parry SE, Reding M, Royall JJ, Schulkin J, Sequeira PA, Slaughterbeck CR, Smith SC, Sodt AJ, Sunkin SM, Swanson BE, Vawter MP, Williams D, Wohnoutka P, Zielke HR, Geschwind DH, Hof PR, Smith SM, Koch C, Grant SGN, Jones AR (2012) An anatomically comprehensive atlas of the adult human brain transcriptome. Nature. 489:391-399. https://doi.org/10.1038/nature11405

Hughes RN (2004) The value of spontaneous alternation behavior $(\mathrm{SAB})$ as a test of retention in pharmacological investigations of memory. Neurosci Biobehav Rev 28:497-505

Hung CY, Tan CH (2018) TRP channels in nociception and pathological pain. Adv Exp Med Biol 1099:13-27. https://doi.org/10.1007/978-981-13-1756-9_2

J. M. Snyder, J. M. Ward, P. M. Treuting, (2016) Cause-of-Death Analysis in Rodent Aging Studies. Veterinary Pathology 53 (2):233-243

Kádková A, Synytsya V, Krusek J, Zímová L, Vlachová V (2017) Molecular basis of TRPA1 regulation in nociceptive neurons. A review. Physiol Res 66:425-439

Kang HJ, Kawasawa YI, Cheng F, Zhu Y, Xu X, Li M, Sousa AM, Pletikos M, Meyer KA, Sedmak G, Guennel T, Shin Y, Johnson MB, Krsnik Z, Mayer S, Fertuzinhos S, Umlauf S, Lisgo SN, Vortmeyer A, Weinberger DR, Mane S, Hyde TM, Huttner A, Reimers M, Kleinman JE, Sestan N (2011) Spatio-temporal transcriptome of the human brain. Nature. 478:483-489. https://doi.org/10.1038/nature10523

Karlsson O, Roman E, Brittebo EB (2009) Long-term cognitive impairments in adult rats treated neonatally with beta-Nmethylamino-L-alanine. Toxicol Sci 112:185-195. https://doi.org/10.1093/toxsci/kfp196

Kaviani E, Rahmani M, Kaeidi A, Shamsizadeh A, Allahtavakoli M, Mozafari N, Fatemi I (2017) Protective effect of atorvastatin on d-galactose-induced aging model in mice. Behav Brain Res 334:55-60. https://doi.org/10.1016/j. bbr.2017.07.029
Keeney JTR, Ren X, Warrier G, Noel T, Powell DK, Brelsfoard JM, Sultana R, Saatman KE, Clair DKS, Butterfield DA (2018) Doxorubicin-induced elevated oxidative stress and neurochemical alterations in brain and cognitive decline: protection by MESNA and insights into mechanisms of chemotherapy-induced cognitive impairment (“chemobrain"). Oncotarget 9:30324-30339. https://doi. org/10.18632/oncotarget.25718

Kheradpezhouh E, Choy JMC, Daria VR, Arabzadeh E (2017) TRPA1 expression and its functional activation in rodent cortex. Open Biol 7:160314. https://doi.org/10.1098 /rsob.160314

Koch M, Kreutz S, Böttger C, Grabiec U, Ghadban C, Korf HW, Dehghani F (2011) The cannabinoid WIN 55,212-2-mediated protection of dentate gyrus granule cells is driven by CB1 receptors and modulated by TRPA1 and Cav 2.2 channels. Hippocampus. 21:554-564. https://doi.org/10.1002 /hipo. 20772

Koivisto A, Chapman H, Jalava N, Korjamo T, Saarnilehto M, Lindstedt K, Pertovaara A (2014) TRPA1: a transducer and amplifier of pain and inflammation. Basic Clin Pharmacol Toxicol 114:50-55. https://doi.org/10.1111/bcpt.12138

Koivisto A, Jalava N, Bratty R, Pertovaara (2018) A TRPA1 antagonists for pain relief. Pharmaceuticals (Basel) 11: E117. https://doi.org/10.3390/ph11040117

Lee KI, Lee HT, Lin HC, Tsay HJ, Tsai FC, Shyue SK, Lee TS (2016) Role of transient receptor potential ankyrin 1 channels in Alzheimer's disease. J Neuroinflammation 13:92. https://doi.org/10.1186/s12974-016-0557-z

Lee KI, Lin HC, Lee HT, Tsai FC, Lee TS (2017) Loss of transient receptor potential ankyrin 1 channel deregulates emotion, learning and memory, cognition, and social behavior in mice. Mol Neurobiol 54:3606-3617. https://doi.org/10.1007 /s12035-016-9908-0

Levin ED (1988) Psychopharmacological effects in the radial-arm maze. Neurosci Biobehav Rev 12:169-175

López-Requena A, Boonen B, Van Gerven L, Hellings PW, Alpizar YA, Talavera K (2017) Roles of neuronal TRP channels in neuroimmune interactions. In: Emir TLR (ed) Neurobiology of TRP channels, 2nd edn. CRC Press/Taylor $\&$ Francis, Boca Raton Chapter 15. Frontiers in Neuroscience

Marighetto A, Valerio S, Jaffard R, Mormede C, Muñoz C, Bernard K, Morain P (2008) The AMPA modulator S 18986 improves declarative and working memory performances in aged mice. Behav Pharmacol 19:235-244. https://doi.org/10.1097/FBP.0b013e3282feb0c1

Meents JE, Ciotu CI, Fischer MJM (2019) TRPA1: a molecular view. J Neurophysiol 121:427-443. https://doi.org/10.1152 /jn.00524.2018

Mitchell SJ, Scheibye-Knudsen M, Longo DL, de Cabo R (2015) Animal models of aging research: implications for human aging and age-related diseases. Annu Rev Anim Biosci 3: 283-303. https://doi.org/10.1146/annurev-animal-022114110829

Morellini F (2013) Spatial memory tasks in rodents: what do they model? Cell Tissue Res 354:273-286

Morgan JA, Singhal G, Corrigan F, Jaehne EJ, Jawahar MC, Baune BT (2018) The effects of aerobic exercise on depression-like, anxiety-like, and cognition-like behaviours over the healthy adult lifespan of C57BL/6 mice. Behav Brain Res 337:193-203. https://doi.org/10.1016/j.bbr.2017.09.022 
Morris RGM (1981) Spatial localization does not require the presence of local cues. Learn Motiv 12:239-260

Müller M, Ahumada-Castro U, Sanhueza M, Gonzalez-Billault C, Court FA, Cárdenas C (2018) Mitochondria and calcium regulation as basis of neurodegeneration associated with aging. Front Neurosci 12:470. https://doi.org/10.3389 /fnins.2018.00470

Nilius B, Appendino G, Owsianik G (2012) The transient receptor potential channel TRPA1: from gene to pathophysiology. Pflugers Arch 464:425-458. https://doi.org/10.1007 /s00424-012-1158-z

Nishida M, Kuwahara K, Kozai D, Sakaguchi R, Mori Y (2015) TRP channels: their function and potentiality as drug targets. In: Nakao K, Minato N, Uemoto S (eds) Basic research and development [Internet]. Springer

Pires PW, Earley S (2018) Neuroprotective effects of TRPA1 channels in the cerebral endothelium following ischemic stroke. Elife 7:e35316. https://doi.org/10.7554/eLife.35316

Pozsgai G, Bátai IZ, Pintér E (2019) Effects of sulfide and polysulfides transmitted by direct or signal transductionmediated activation of TRPA1 receptors. Br J Pharmacol 176:628-645. https://doi.org/10.1111/bph.14514

Reglodi D, Atlasz T, Szabo E, Jungling A, Tamas A, Juhasz T, Fulop BD, Bardosi A (2018) PACAP deficiency as a model of aging. Geroscience. 40:437-452. https://doi.org/10.1007 /s11357-018-0045-8

Sághy É, Sipos É, Ács P, Bölcskei K, Pohóczky K, Kemény Á, Sándor Z, Szőke É, Sétáló G Jr, Komoly S, Pintér E (2016) TRPA1 deficiency is protective in cuprizone-induced demyelination-a new target against oligodendrocyte apoptosis. Glia 64:2166-2180

Shigetomi E, Tong X, Kwan KY, Corey DP, Khakh BS (2011) TRPA1 channels regulate astrocyte resting calcium and inhibitory synapse efficacy through GAT-3. Nat Neurosci 15 : 70-80. https://doi.org/10.1038/nn.3000

Shigetomi E, Jackson-Weaver O, Huckstepp RT, O’Dell TJ, Khakh BS (2013) TRPA1 channels are regulators of astrocyte basal calcium levels and long-term potentiation via constitutive D-serine release. J Neurosci 33:10143-10153. https://doi.org/10.1523/JNEUROSCI.5779-12.2013

Storozhuk MV, Zholos AV (2018) TRP channels as novel targets for endogenous ligands: focus on endocannabinoids and nociceptive signalling. Curr Neuropharmacol 16:137-150. https://doi.org/10.2174/1570159X15666170424120802

Sudduth TL, Powell DK, Smith CD, Greenstein A, Wilcock DM (2013) Induction of hyperhomocysteinemia models vascular dementia by induction of cerebral microhemorrhages and neuroinflammation. J Cereb Blood Flow Metab 33:708715. https://doi.org/10.1038/jcbfm.2013.1

Sun B, Bang SI, Jin YH (2009) Transient receptor potential A1 increase glutamate release on brain stem neurons. Neuroreport. 20:1002-1006. https://doi.org/10.1097 /WNR.0b013e32832d2219

Sure VN, Sakamuri SSVP, Sperling JA, Evans WR, Merdzo I, Mostany R, Murfee WL, Busija DW, Katakam PVG (2018) A novel high-throughput assay for respiration in isolated brain microvessels reveals impaired mitochondrial function in the aged mice. Geroscience 40:365-375. https://doi. org/10.1007/s11357-018-0037-8

Takizawa M, Harada K, Nakamura K, Tsuboi T (2018) Transient receptor potential ankyrin 1 channels are involved in spontaneous peptide hormone release from astrocytes. Biochem Biophys Res Commun 501:988-995. https://doi. org/10.1016/j.bbrc.2018.05.097

Tan BL, Norhaizan ME, Liew WP, Sulaiman Rahman H (2018) Antioxidant and oxidative stress: a mutual interplay in agerelated diseases. Front Pharmacol 9:1162. https://doi. org/10.3389/fphar.2018.01162

Tenk J, Rostás I, Füredi N, Mikó A, Solymár M, Soós S, Gaszner B, Feller D, Székely M, Pétervári E, Balaskó M (2017) Agerelated changes in central effects of corticotropin-releasing factor (CRF) suggest a role for this mediator in aging anorexia and cachexia. Geroscience. 39:61-72. https://doi. org/10.1007/s11357-017-9962-1

Ungvari Z, Valcarcel-Ares MN, Tarantini S, Yabluchanskiy A, Fülöp GA, Kiss T, Csiszar A (2017) Connective tissue growth factor (CTGF) in age-related vascular pathologies. Geroscience. 39: 491-498. https://doi.org/10.1007/s11357-017-9995-5

Vedovelli K, Giacobbo BL, Corrêa MS, Wieck A, Argimon IIL, Bromberg E (2017) Multimodal physical activity increases brain-derived neurotrophic factor levels and improves cognition in institutionalized older women. Geroscience. 39:407417. https://doi.org/10.1007/s11357-017-9987-5

Wahl D, Coogan SC, Solon-Biet SM, de Cabo R, Haran JB, Raubenheimer D, Cogger VC, Mattson MP, Simpson SJ, Le Couteur DG (2017) Cognitive and behavioral evaluation of nutritional interventions in rodent models of brain aging and dementia. Clin Interv Aging 12:1419-1428. https://doi. org/10.2147/CIA.S145247

Y.-F. Li, Y.-F. Cheng, Y. Huang, M. Conti, S. P. Wilson, J. M. O'Donnell, H.-T. Zhang, (2011) Phosphodiesterase-4D KnockOut and RNA Interference-Mediated Knock-Down Enhance Memory and Increase Hippocampal Neurogenesis via Increased cAMP Signaling. Journal of Neuroscience 31 (1): $172-183$

Yohan D'Souza, Ahmed Elharram, Raquel Soon-Shiong, R David Andrew, Brian M Bennett, (2015) Characterization of Aldh2 -/- mice as an age-related model of cognitive impairment and Alzheimer's disease. Molecular Brain 8 (1)

Yokoyama T, Ohbuchi T, Saito T, Sudo Y, Fujihara H, Minami K, Nagatomo T, Uezono Y, Ueta Y (2011) Allyl isothiocyanates and cinnamaldehyde potentiate miniature excitatory postsynaptic inputs in the supraoptic nucleus in rats. Eur J Pharmacol 655:31-37. https://doi.org/10.1016/j.ejphar.2011.01.011

Zhang HT, Crissman AM, Dorairaj NR, Chandler LJ, O'Donnell JM (2000) Inhibition of cyclic AMP phosphodiesterase (PDE4) reverses memory deficits associated with NMDA receptor antagonism. Neuropsychopharmacology 23(2): 198-204. https://doi.org/10.1016/S0893-133X(00)00108-1

Zhang R, Xue G, Wang S, Zhang L, Shi C, Xie X (2012) Novel object recognition as a facile behavior test for evaluating drug effects in A $\beta P P / P S 1$ Alzheimer's disease mouse model. J Alzheimers Dis 31:801-812. https://doi.org/10.3233/JAD2012-120151

Zygmunt PM, Högestätt ED (2014) TRPA1. Handb Exp Pharmacol 222:583-630. https://doi.org/10.1007/978-3642-54215-2_23

Publisher's note Springer Nature remains neutral with regard to jurisdictional claims in published maps and institutional affiliations. 